\title{
The discourse of design: Patterns of TPACK Contribution during pre-service teacher learning design conversations
}

\author{
Giang N. H. Nguyen ${ }^{1}$ (D) Matt Bower ${ }^{2} \cdot$ Michael Stevenson $^{3,4}$
}

Received: 12 December 2021 / Accepted: 31 January 2022 / Published online: 3 March 2022

(c) The Author(s), under exclusive licence to Springer Science+Business Media, LLC, part of Springer Nature 2022

\begin{abstract}
Analysing pre-service teachers' learning design conversations in relation to Technological Pedagogical and Content Knowledge (TPACK) framework to understand their learning design practices has remained unexplored. This paper presents findings from a study of pre-service teachers' design discourses that identified how TPACK elements were used during their collaborative design of technology-enhanced lessons. Through thematic analysis of 81 design conversations in two cycles, it was found that pre-service teachers discussed design related issues, TPACK elements, and context in their design conversations with dominant references to design-related issues, substantial occurrences of single TPACK elements, and lower frequencies of integrated TPACK elements and context. Practical recommendations and a DesignTPACK or 'D-TPACK' framework were proposed to support pre-service teachers' learning design practices.
\end{abstract}

Keywords Pre-service teachers · Teacher education · Learning design · Discourse analysis · Thematic analysis · TPACK · Collaborative design · Design knowledge

\section{Introduction}

It is critical that educational institutions develop teachers' abilities to design learning tasks using technology, positioning them as active designers of their own technology-enhanced lessons. The teacher's roles as learning designer has been recognised and encouraged by policy-makers (ISTE, 2022; UNESCO, 2018), as

Giang N. H. Nguyen

giangnnh@hanu.edu.vn

1 Hanoi University, Hanoi, Vietnam

2 School of Education, Macquarie University, Sydney, Australia

3 New South Wales Department of Education, Parramatta, Australia

4 Macquarie University, Sydney, Australia 
well as supported in the literature (Nguyen \& Bower, 2018; Laurillard, 2013). The COVID-19 pandemic has prompted educational institutions and teachers in both developed and developing countries to transform from face-to-face and blended forms of learning into completely online learning. This forced transformation has made it more significant than ever for teachers to be active designers of their own online modules.

A number of strategies (e.g. Chai et al., 2019; Dagnino et al., 2018; McKenney et al., 2015; Svihla et al., 2015; Tondeur et al., 2012) and tools (e.g. Asensio-Pérez et al., 2017; Bennett et al., 2015; Bower, 2012; Bower et al., 2011; Katsamani et al., 2012) have been suggested to support developing teacher learning design capabilities. Also, researchers have proposed and investigated interventions to improve teacher learning design capabilities (Nguyen \& Bower, 2018; Tondeur et al., 2020). Yet much of this work has occurred without an in-depth understanding of what actually happens when teachers are designing. Without a clear picture of what occurs during design, it is difficult to know what sort of problems may be occurring, and therefore the sorts of teacher education strategies that are likely to be most effective.

There has been research that has examined learning design processes that inservice teachers adopt (e.g. Bennett et al., 2015; Koh \& Chai, 2016; McKenney et al., 2016; Zhang et al., 2019). Yet pre-service teachers who are a critical cohort to understand in terms of their more novice design practices have received less attention. With less pedagogical, curricular, and practical experience there may be quite different approaches to learning design based on naive understanding, thus requiring quite different support to help them design effectively.

In addition, the development of teacher learning design has been argued to revolve around having Technological, Pedagogical, and Content Knowledge - or 'TPACK' understanding (Boschman et al., 2015; Chai et al., 2019; Graham et al., 2012; Koehler \& Mishra, 2009; Koh \& Chai, 2016; Tondeur et al., 2020). TPACK has been used as a lens for examining design discourses, but usually in limited manner, and never comprehensively for pre-service teachers.

To provide the field with a clear understanding of how pre-service teachers engage in learning design processes, this study conducted a rigorous examination of six triads $(n=18)$ of pre-service teachers over several weeks as they collaboratively created technology-enhanced learning designs for their prospective students. Specifically, this project addressed the research question:

- How, in what ways, and to what extent do pre-service teachers focus on elements of TPACK and Design Knowledge (DK) when collaboratively designing technology-mediated lessons?

\section{Literature review}

Extending from the Pedagogical Content Knowledge (PCK) framework established by Shulman (1986) and theorised by Mishra and Koehler (2006), TPACK stands for Technological, Pedagogical, and Content Knowledge and includes seven 
components: Technology Knowledge (TK), Content Knowledge (CK), Pedagogical Knowledge (PK), Pedagogical Content Knowledge (PCK), Technological Content Knowledge (TCK), Technological Pedagogical Knowledge (TPK) and Technological, Pedagogical Content Knowledge (TPACK). At the core of the framework is the concept of TPACK where there is a complex interplay of the three primary elements of knowledge: TK, CK and PK. Effective integration of technology in teaching goes beyond considering each element individually (Koehler \& Mishra, 2009). Effective technology-enhanced teaching and learning require comprehensive understanding of what teaching strategies to use with what content and what technologies in certain contexts (Koehler \& Mishra, 2009).

Recent research has examined the nature of collaborative design conversations using the TPACK framework to determine the knowledge domains on which teachers placed the most emphasis (Boschman et al., 2015; Koh \& Chai, 2016; Tseng et al., 2019; Zhang et al., 2019). Interestingly, it was found that experienced in-service teachers predominantly discussed issues related to PCK and TPACK in their design discourses (Boschman et al., 2015; Koh \& Chai, 2016; Zhang et al., 2019). More interestingly, pre-service teachers were found to hardly mention TPK (Tseng et al., 2019), leading to a hypothesis that all the TPACK knowledge elements are not necessarily enacted during the design conversations owing to the uniqueness and complexities associated with each context. Moreover, non-TPACK matters relating to design processes or aesthetic aspects of the designs were identified in discussions (Nguyen \& Bower, 2018; Koh \& Chai, 2016). As background to understand the role that different TPACK and design discourse can play during design conversations, key empirical findings from the literature are summarised below.

\subsection{Technological Knowledge (TK)}

Technology Knowledge (TK) is one area of the learning design processes that teachers identify as an important area to focus upon in their design work (Churchill, 2006; Graham et al., 2012). However, TK is often not a major feature in teachers' design group discussions. Kindergarten teachers in Boschman et al.'s study (2015) hardly discussed technology in their design talks (7 out of 65 counts of the units coded). In line with this finding, discussions related to technology accounted for only $3.25 \%$ of the units coded in primary teachers' design talks in Koh and Chai's study (2016). Zhang et al. (2019) also found that TK owned by primary teacher participants had the lowest distribution frequency ( $2.3 \%$ of the units coded) on forum posts. This limited attention to TK has also been observed among pre-service teachers. Janssen and Lazonder (2016) found few technology-related units coded in 54 pre-service teachers' justifications for their lesson plans. Similarly, discussions related to technology constituted only 7 out of 59 counts of the discourse episodes coded in Tseng et al.'s study (2019). On the other hand, technology was among the main focuses of design conversations among pre-service teachers in a pilot study conducted prior to the present study (Nguyen \& Bower, 2018). 


\subsection{Pedagogical Knowledge (PK)}

Further research reveals that teachers also consider Pedagogical Knowledge (PK) - that is, knowledge of their own teaching strategies, assessment, and class management in their design processes, making pedagogy another basis for design practices (Bennett et al., 2015; Churchill, 2006; Graham et al., 2012; Postareff \& Lindblom-Ylänne, 2008). Primary teachers in Zhang et al.'s study (2019) discussed pedagogy 87 times, accounting for $15.5 \%$ of the units coded. PK-related discussions represented 5 out of 59 counts (8.5\%) among pre-service teachers' discourse episodes in Tseng et al.'s study (2019). On the other hand, pedagogy was rarely mentioned by teachers during their design conversations in some studies (Nguyen \& Bower, 2018; Boschman et al., 2015). While the pre-service teachers in Nguyen and Bower's (2018) study reported a backwards approach where they designed their technology-enhanced online courses first and then thought about what pedagogical approaches underpinned the designed learning activities at a later stage when they needed to write up justifications for their designs, more experienced teachers (with 30 years teaching experience on average) in Boschman et al.'s study (2015) discussed PK in relation to content or content and technology though they did not discuss pedagogy separately. The gap between years of teaching experience could be an explanation for the difference in why pedagogy was largely absent in each study. Another underlying reason might be that Nguyen and Bower (2018) did not explore teachers' design talks using the TPACK framework whereas Boschman et al. (2015) did. This indicates the need for design talks among pre-service teachers to be examined and coded against the TPACK knowledge elements.

\subsection{Content Knowledge (CK)}

Content Knowledge (CK) has been influential to teacher learning design practices (Bennett, 2013; Bennett et al., 2016; Churchill, 2006; Graham et al., 2012; Harris \& Hofer, 2011; McKenney et al., 2016; Nguyen \& Bower, 2018). CK has been conceptualised as learning outcomes (Bennett, 2013), goals, objectives, and themes in early literacies (McKenney et al., 2016), the knowledge of learners' prior knowledge, and the misconceptions as well as the problems with certain content (Graham et al., 2012). CK has also characterised many teachers' collaborative design conversations, albeit with lower frequencies compared to other knowledge elements, accounting for 3.8\%, 6.3\%, and 7.7\% of the units coded in the respective studies conducted by Koh and Chai (2016), Zhang et al. (2019), and Boschman et al. (2015). Tseng et al. (2019) discovered a higher frequency of content knowledge among pre-service teachers who discussed their learning designs in groups (roughly $17 \%$ of the units coded). 


\subsection{Pedagogical Content Knowledge (PCK)}

Teachers have also been observed to discuss issues related to Pedagogical Content Knowledge (PCK) while designing their technology-based lesson plans and modules. In several studies, teachers referred predominantly to PCK when they discussed or provided rationales for their technology-enhanced lessons (Boschman et al., 2015; Janssen \& Lazonder, 2016; Koh \& Chai, 2016; Tseng et al., 2019; Zhang et al., 2019). For example, in studies by Koh and Chai (2016) and Zhang et al. (2019) PCK dominated the teachers' design discussions, with over $37 \%$ and $55 \%$ of the units coded respectively. These higher frequencies were due to primary teachers often utilising teaching methods to teach stories and songs while rarely considering the use of technology (Zhang et al., 2019).

\subsection{Technological Pedagogical Knowledge (TPK)}

Teachers' design conversations are also characterised by their discussions on their choices of Technological Pedagogical Knowledge - that is, certain technological resources for certain teaching and class management strategies in designing their lessons (Graham et al., 2012; Koh \& Chai, 2016; Tseng et al., 2019). Discussions related to TPK were marginal as indicated by their low distribution, just under $1 \%$ of the units coded (Koh \& Chai, 2016) or even none (Tseng et al., 2019). Tseng et al. (2019) explained that the absence of TPK was due to the platform (Adobe Connect) the participants used to design technology-based lessons in that it constrained teachers' integration of more technologies, especially when they designed technology-enhanced teaching material on PowerPoint. This finding leads to a confirmation by the researchers that all the knowledge elements conceptually coined by Mishra and Koehler (2006) are not necessarily enacted during the design conversations owing to the uniqueness and complication of context.

\subsection{Technological Content Knowledge (TCK)}

Teachers have also been observed discussing technology in relation to content, evidencing Technology Content Knowledge (TCK) through their design conversations. However, like TPK, TCK in Koh and Chai's study (2016) received hardly any attention during teachers' design conversations, $0.66 \%$ of the units coded. In a study on 81 primary teachers' TPACK via collaborative learning design practices, Zhang et al. (2019) also identified discussion on TCK as having the lowest distribution (2.3\%). The justification the researchers provided for this finding was that teachers of younger years in the study seldom used technology to teach content, instead mostly combining pedagogy with content. Similarly, Tseng et al. (2019) identified TCK as least counted (4 of 59 counts) in both early and later stages of the study. 


\subsection{Technological Pedagogical Content Knowledge (TPACK)}

TPACK discourses can be defined as "discussions related to the use of ICT to support particular pedagogies for particular subject content" (Koh \& Chai, 2016, p. 248). TPACK has been found to be one of the areas of focus of teachers in designing their technology-based lessons (Graham et al., 2012), especially in their learning design conversations (Koh \& Chai, 2016; Tseng et al., 2019; Zhang et al., 2019). It constituted nearly $20 \%$ of the units coded in Koh and Chai's study of practising teachers (2016) and over 15\% of the units coded in Zhang et al.'s study (2019). In contrast, both TPACK distribution in pre-service teachers' rationales for their lesson plans and the TPACK quality of the lesson plans were found to be low (Janssen \& Lazonder, 2016). The researchers, also teacher educators, speculated that the low quality of TPACK might be because they only provided pre-service teachers with the content and pedagogy guidance, with minimal guidance on how and why to integrate technology, pedagogy, and content. This suggests TPACK improvement is influenced by various contextual factors including teacher educators' teaching strategies, hence the need for further research on this area.

\subsection{Design Knowledge (DK)}

In addition to the seven TPACK knowledge domains, evidence suggests that pre-service teachers also focus on knowledge relating to the design process itself. In their study, Koh and Chai (2016) coded this emergent dimension as Design Knowledge (DK), which in their study constituted more than $34 \%$ of the units coded. Issues discussed by their participants pertained to the design strategies like choosing design goals, determining where to save their design drafts, and delegating tasks among themselves. Similar design-related themes like scheduling, task distribution, aesthetic options, and common ground awareness establishment were also found in Nguyen and Bower's (2018) study. Koh and Chai (2016) emphasised the pivotal role of DK when applying TPACK knowledge during the design process and recommended it as "an area warranting further consideration" (p. 255).

\subsection{Context}

The teaching and learning context is considered an influential and inseparable factor in the learning design process (Bennett et al., 2011, 2015; Boyle \& Ravenscroft, 2012; Harris \& Hofer, 2011). Although context has been considered a central element in the TPACK framework by its developers (Mishra \& Koehler, 2006; Koehler \& Mishra, 2009), there is prior evidence that context was frequently missing when researchers described, explained, or operationalised TPACK (Rosenberg \& Koehler, 2015), or when teachers discussed their technology-enhanced designs (Nguyen \& Bower, 2018). The nature of context varied widely from micro factors like classroom, material cost, and workload, meso factors like curriculum, school, teachers, and student to macro factors like leadership and society (Bennett et al., 2011; Harris 
\& Hofer, 2011; Rosenberg \& Koehler, 2015). The occurrence of context-related discourse is important to examine because of its critical role in learning design processes, though earlier research found that without external encouragement preservice teachers do not tend to focus upon context as part of their learning design conversations (Nguyen \& Bower, 2018).

\subsection{Critical observations from analysis of the empirical literature}

Several observations could be drawn out of the learning design studies in relation to TPACK reviewed above. The first general observation is that design thinking in a design process has been approached in three different ways. First, design thinking is in the form of teachers' design intentions in certain scenarios where teachers provide rationales for their design decisions (Graham et al., 2012). In this case, participants did not engage in a real design process. Second, most studies elicited participants' retrospective learning design process via interviews (e.g. Bennett et al., 2015) or reflective reports/forum posts (Zhang et al., 2019). Third, although participants worked together and were involved in a design process in the Zhang study, they only planned a technology-based lesson, rather than creating modules or products (Zhang et al., 2019). There is, therefore, a lack of investigations of teachers' design thinking and decision making while engaging in the real-time and actual process of designing an online TEL artefact.

In addition, in some projects, teachers' design thinking was examined individually; in others, collaboratively. Individual teachers' design thinking was often examined using forum posts, interviews, reflections, lesson plans, or surveys with collaborative data usually collected in the form of interviews or recordings. Some studies claimed to adopt and examine a collaborative design process, but the whole process was not fully collaborative; that is, participants discussed online together as a cohort via forum posts, but each teacher came up with an individual TEL lesson plan as a product (Zhang et al., 2019). A fully collaborative approach to learning design in this current study means members of each group worked together from the beginning (planning) until the final stage when they came up with a complete technology enhanced learning module.

Furthermore, most studies were conducted on experienced in-service teachers, with researchers often underscoring the need for further research on pre-service teachers for a better insight or comparison. Koh and Chai (2016) emphasised there should be more investigation into pre-service design frames so that comparisons between the design frames of pre-service teachers and in-service teachers could be carried out, from which teacher educators were able to "distinguish the pedagogical approaches for supporting design work in pre-service and in-service ICT courses" (p. 255). Similarly, examining design talks by pre-service teachers might lead to different results especially in PCK because of in-service and pre-service teacher differences in pedagogical capabilities (Koh et al., 2014).

In light of the above gaps in the teacher education and learning design fields, and as mentioned earlier in the paper, this current study set out to answer the following question: 
- How, in what ways, and to what extent do pre-service teachers focus on elements of TPACK and Design Knowledge (DK)when collaboratively designing technology-mediated lessons?

Findings from this study can directly inform the design of teacher education in the use of technology.

\section{Method}

\subsection{Setting}

This study used a qualitative approach to investigating the knowledge elements preservice teachers focused upon while designing their technology-enhanced lessons in groups through two cycles happening in two consecutive years. Data were collected from an undergraduate tertiary teacher education unit entitled [anonymised for peer review]. Weekly tutorials were held in the physical classroom supported by the unit's online content and learning activities located on the university's learning management system. The unit was a full semester course that contained ten face-to-face weeks including a one-hour lecture and a two-hour tutorial each week. Data were collected during pre-service teachers' design activities from Tutorials 5-6 to Tutorial 10.

The design task involved students working in groups of three to design and develop a module of work within Moodle, a popular open-source Learning Management System. The Moodle module needed to relate to one or more learning outcomes for any state-based syllabus key learning areas with a duration of two 50-minute lessons per person in the group. In addition, each student had to submit an 800-word written justification of the design they had created. The justification needed to be theoretically informed and describe how the module had been designed to help students achieve the pre-identified syllabus outcomes. In each Moodle week, the groups were given 25-40 min on average to work on their collaborative Moodle designs. The assignment structure in both cycles was very similar except for two minor changes in Cycle 2. One was that specific real-life contexts (websites of two schools) were provided in Cycle 2 in addition to a default general context in which participants could situate their designs. Another change was extra time dedicated to in-class group design conversations (on average from 25 min each in CYCLE 1 to 40 min each in Cycle 2) and more time allotted to the Moodle collaborative task (6 Moodle weeks in Cycle 2 instead of 5 Moodle weeks in Cycle 1).

\subsection{Participants}

Participants were primary pre-service teachers pursuing a Bachelor of Arts with the degree of Bachelor of Education. Those who agreed to participate were arranged into groups of three based on several other factors such as the class in which they were enrolled, their preferred group partners, their preferred syllabus area(s), and their confidence about using technology in general, using technology to design 


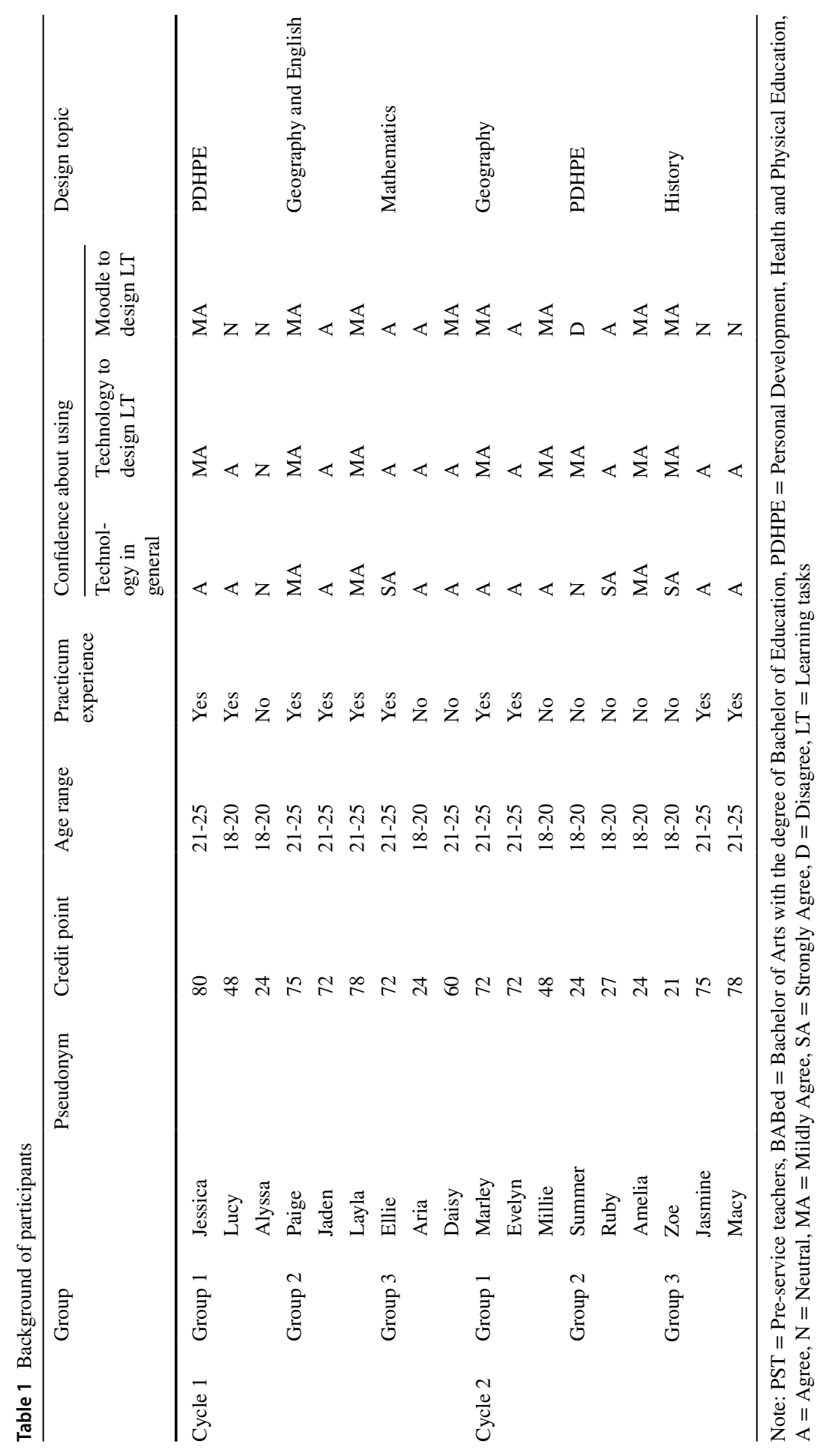


learning tasks, and using Moodle in particular (in that order of priority). Enrolling in the same class was number one priority criterion for the purpose of investigating collaborative learning design practices. Three groups of three students were observed in each Cycles 1 and 2, resulting in 18 pre-service teacher participants. Table 1 details these 18 pre-service teachers' profiles.

\subsection{Data collection}

Data were collected via recording of design conversations including face-to-face inclass group discussions and Facebook Messenger online group chats. The former captured the pre-service teachers' 'live' design thinking over during designated tutorial discussion time in each Moodle week. The latter also captured 'live' thoughts in online chats that occurred outside of class time. The recording of group discussions took place every Moodle week, from Tutorial 6 to Tutorial 10 (5 weeks) for Cycle 1 and from Tutorial 6 to Tutorial 10 plus the last review week (6 weeks) for Cycle 2 . Like other groups, the selected groups were given $25 \mathrm{~min}$ on average in Cycle 1 and 40 min on average in Cycle 2 to collaborate. In total, there were 33 transcripts of inclass discussions and 48 online chats collected, screened, and analysed.

\subsection{Data analysis}

Discourses of in-class design conversations and Facebook chats were analysed adopting the thematic analysis approach defined as "a method for identifying, analysing and reporting patterns (themes) within data" (Braun \& Clarke, 2006, p. 79). The whole data analysis process strictly complied with Braun and Clarke's (2006) six-phased procedures including (1) familiarisation with the data, (2) Coding, (3) Searching for themes, (4) Reviewing themes, (5) Defining and naming themes, and (6) Producing the report (refer to Nguyen (2020) for step-by-step six-phased procedures with detailed explanations and specific examples). Constant moving back and forth between phases and reflections occurred over time to uphold the quality and integrity of the analysis. Simultaneously, trustworthiness was addressed via detailed and systematic documentation, continual critical reflection, thorough and thoughtful approaches to explanation, ongoing triangulation and continuous engagement with the data, as recommended strategies to improve the reliability and validity of findings (Maguire \& Delahunt, 2017; Nowell et al., 2017).

Sentences, as fine-grained units, were chosen as units of analysis to provide greater distribution of codes, enabling the emergence of patterns of collaborative design and issues related to them (Bower, 2009). Also, breaking down transcribed textual data by sentence showed that syntactical differences rather than semantic differences were used to identify the textual units and therefore introducing bias to the data prior to coding could be avoided (Koh \& Chai, 2016). In this current study, no sentences were double coded; that is, each sentence was coded once.

The coding scheme was based on two different coding protocols developed by Koh and Chai (2016) and Nguyen and Bower (2018), resulting in a preliminary coding framework including nine initial categories as shown in Table 2. 


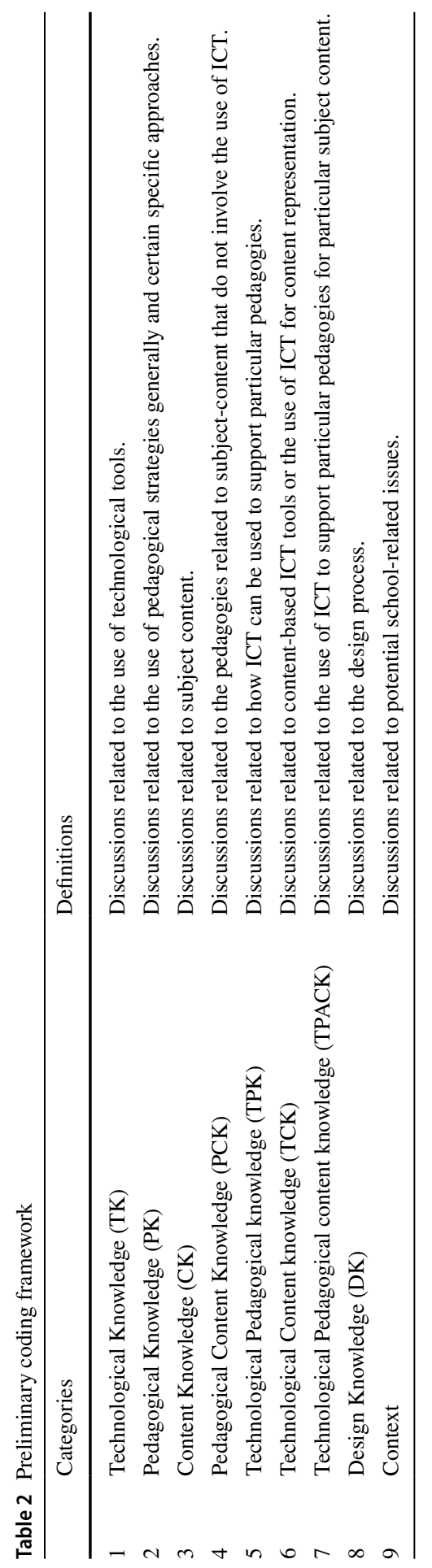




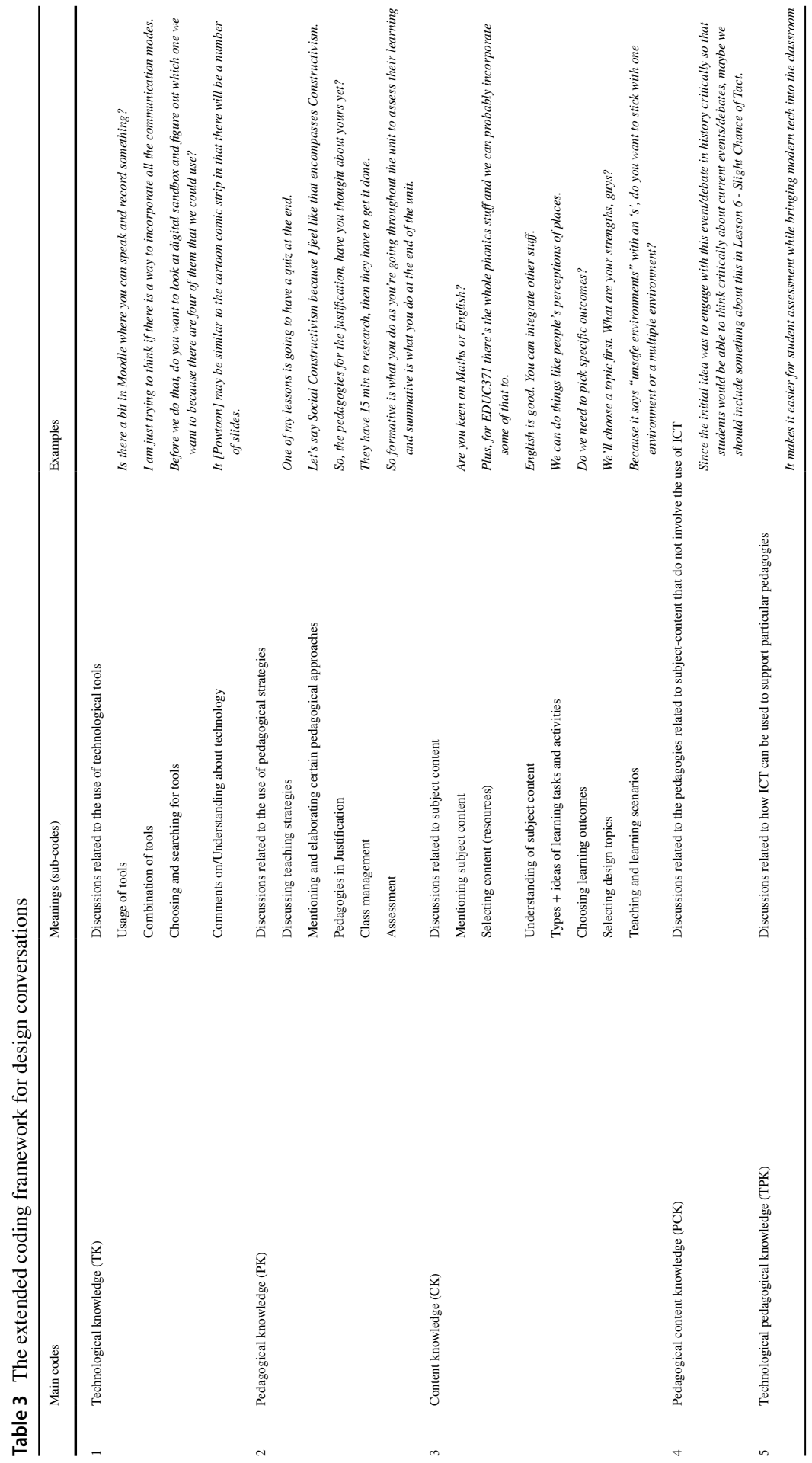




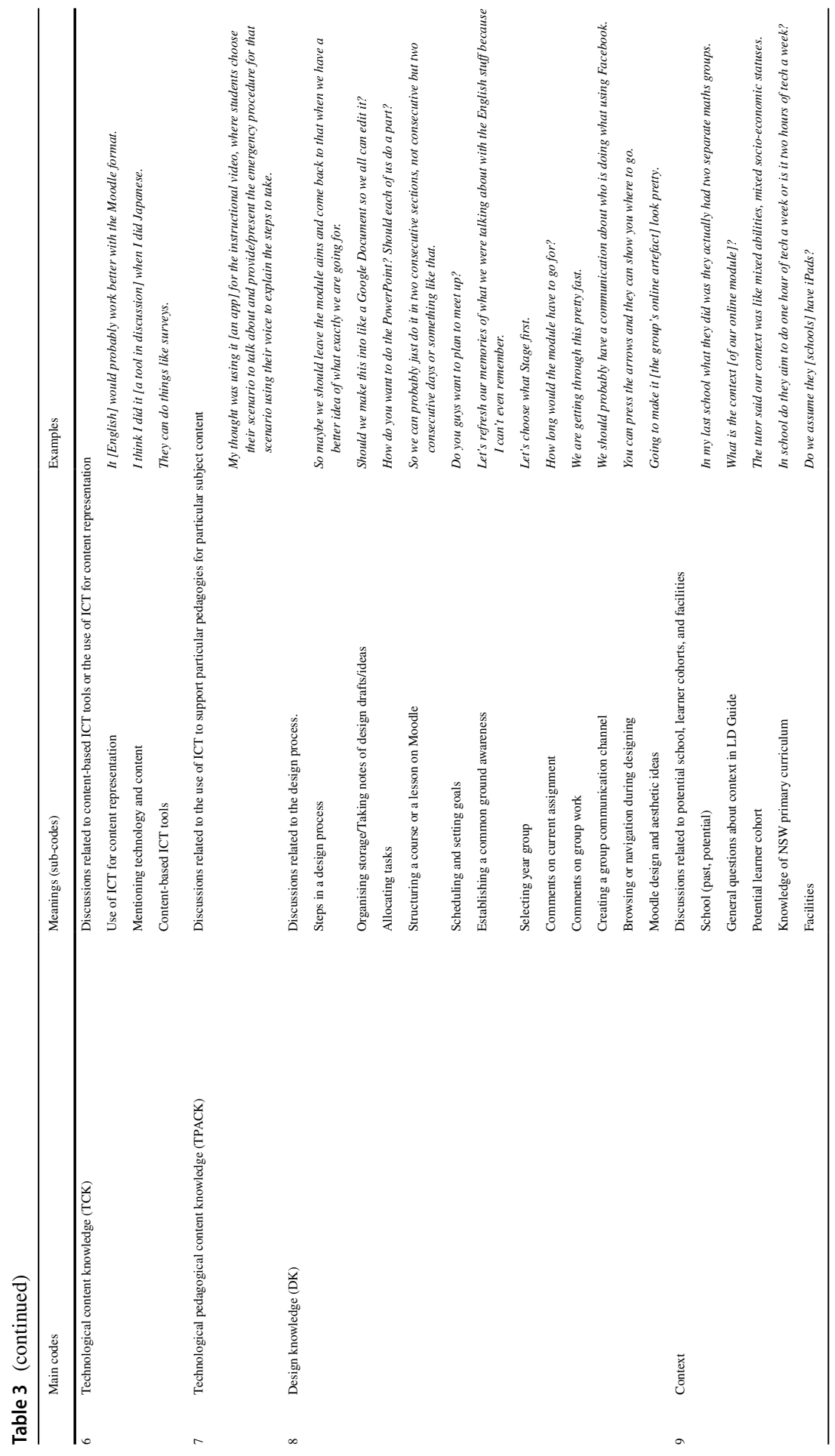


An abductive approach to coding was applied, which involved both inductive and deductive approaches. That is, although there was an a priori list of categories, the researcher was prepared for unexpected emergence of further categories and/or subcategories. Table 3 shows an extended coding framework for the design conversations (involving 35 sub-categories) that includes names of codes, the meanings identified by them, and examples of the coded segments. There were around 11,000 sentences coded.

An independent coder was invited to code a randomly-selected transcript in each iteration. The weighted average Kappa coefficient was then calculated, weighted according to the percentage of the transcript coded by each node. Similarly, the weighted average percentage agreement was calculated, weighted by the amount of transcript coded by each node. The respective average Kappa score weighted by coding coverage for Cycle 1 and Cycle 2 were 0.813 and 0.853 , the strength of agreement of which were deemed as almost perfect by Landis and Koch (1977). The respective average percentage agreement weighted by coding coverage were 0.738 and 0.781 for Cycle 1 and Cycle 2. The percentage agreement gained from both approaches to calculating was considered to be high, hence providing confidence in the reliability of the coding.

\section{Findings}

Figures 1 and 2 show the frequency distribution of units when coded for seven TPACK constructs, Design Knowledge (DK), and Context (C) categories in Cycle 1 and Cycle 2 respectively. It can be seen from Fig. 1that issues related to DK, CK, $\mathrm{PK}$, and TK dominated the pre-service teachers' Cycle 1 design conversations, constituting nearly $85 \%$ of the units coded. The pre-service teachers did not often focus on TPACK and TCK as these only constituted approximately $10 \%$ of the units coded. The other elements - PCK, C, and TPK - occurred least frequently with only $2.9 \%, 1.9 \%$ and $0.8 \%$ of the discussions respectively. Similarly, DK, CK, PK, and TK were also the dominant references in Cycle 2, accounting for almost $90 \%$ of

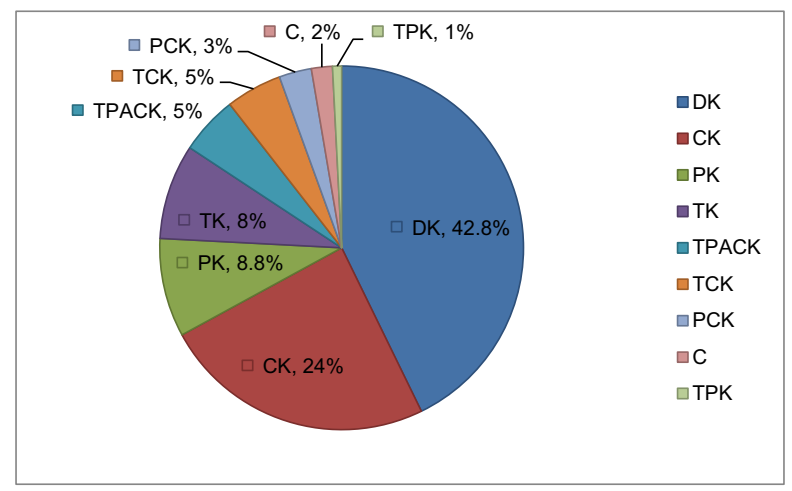

Fig. 1 Distribution of design focuses in Cycle 1 


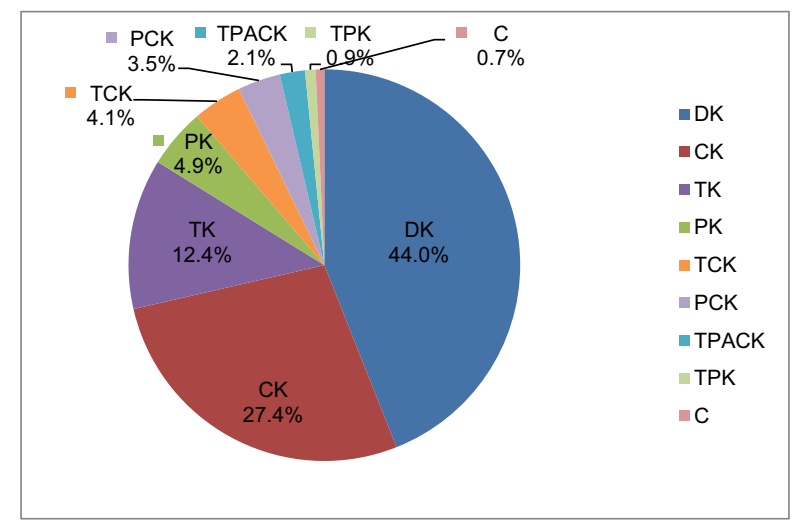

Fig. 2 Distribution of design focuses in Cycle 2

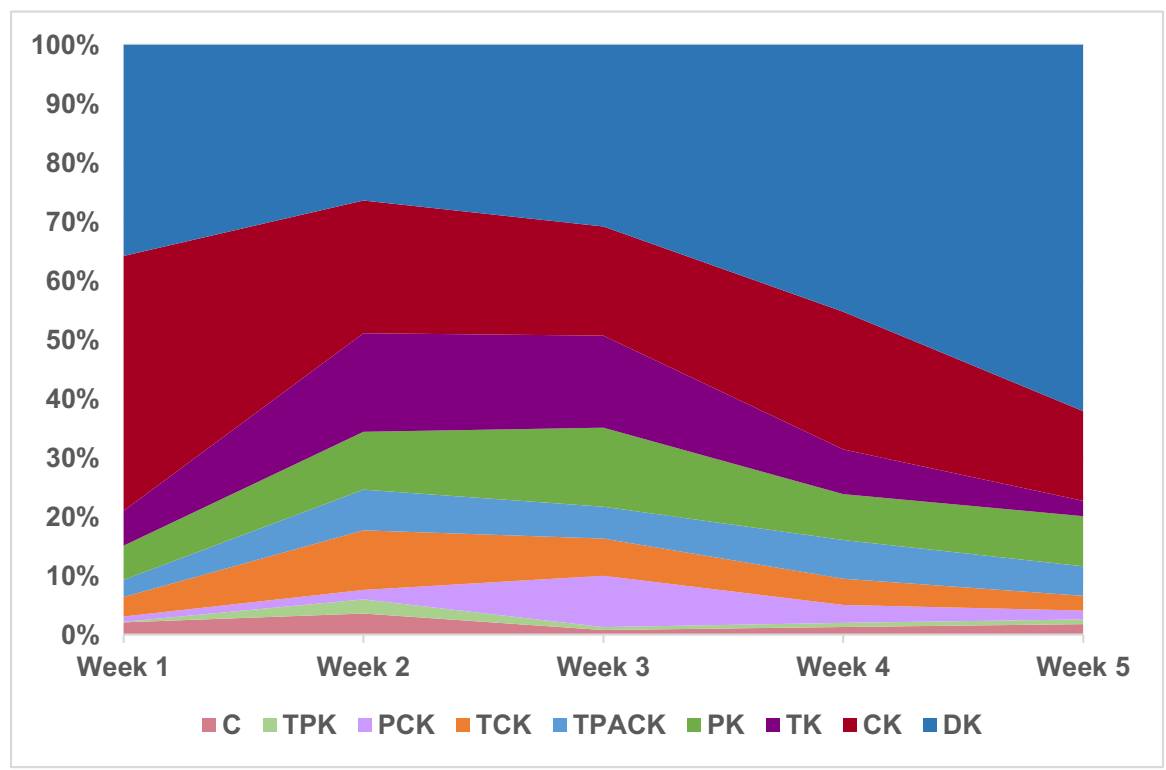

Fig. 3 Stacked percentage distribution of design conversation focuses across weeks for Cycle 1

the units coded in Cycle 2 (Fig. 2). The remaining 10\% was allocated among TCK, PCK, TPACK, TPK, and C $(4.1 \%, 3.5 \%, 2.1 \%$, and $0.7 \%$ respectively).

The distributions of different elements indicate the remarkable consistency between the two Cycles 1 and 2. Figures 3 and 4 provide stacked bar graphs to illustrate the distribution of discourse categories across the different weeks of the design process for Cycle 1 and 2. The frequencies of the different discourse categories for Cycle 1 and Cycle 2 are provided in Tables 4 and 5 of the Appendix, for completeness. The following sub-sections provide a more detailed qualitative 


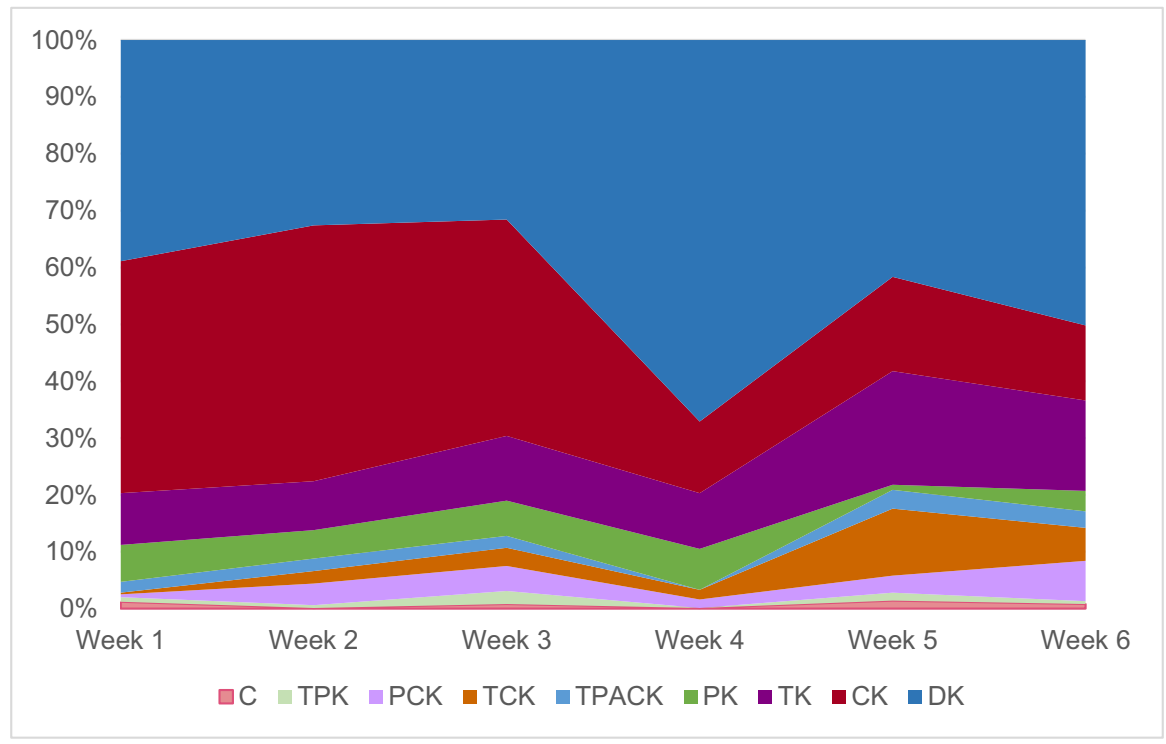

Fig. 4 Stacked percentage distribution of design conversation focuses across weeks for Cycle 2

exposition for each element across both cycles, with elements presented in descending order of frequency for the two cycles combined.

\subsection{Design Knowledge (DK)}

In both cycles, pre-service teacher groups placed considerable emphasis (well over $40 \%$, as indicated in Figs. 1 and 2) on discussing non-TPACK issues that were related to the whole design process such as allocating tasks (e.g. Do you guys have any preferences about which two lessons you want to do?), creating a group communication channel (e.g. Let's make a group chat [via Facebook Messenger].), making schedules and setting up design goals for the next group meeting (e.g. I know we're all short on time, but I think it'd be good to actually have something on our Moodle before Monday.), and establishing a common-ground awareness (e.g. [Let's] summarise first before we go anywhere.). Interestingly, in the DK data in both cycles, all design conversations evidently shared a similar pattern (see Figs. 3 and 4). Each Week 1 in-class discussion consistently involved introductions and sharing of background so that they could pick an appropriate design topic for the Moodle modules. Across the weeks, there were times the team members would distribute tasks amoung group members and create a collective communication channel like Facebook Messenger. After the first week, at the beginning of each design talk, the teams would typically aim to establish a common-ground awareness by summarising what they had finished or had not been able to do yet in the previous week. All teams sought a way (e.g. using 
Google Docs) to store and share their design drafts or ideas. Teams evidently focused more on the design aspects in the latter weeks for both cycles (refer to Tables 4 and 5 in the Appendix for specific counts of occurrences).

\subsection{Content Knowledge (CK)}

CK discussions were substantial, with high frequencies across all the weeks $(24.3 \%$ and $27.4 \%$ for Cycle 1 and Cycle 2 as shown in Figs. 1 and 2 respectively). The groups' content-related conversations revolved around the subject matter learning outomes (e.g. If it is Geography and English, how many outcomes are going to be the limit?), design topics (e.g. I think we need to choose tesselation or 3D shapes), content dot points and resources (e.g. Here's another thing I found accidentally you could use for exploring the Aboriginal perspective of caring for the Country.), types of learning tasks (e.g. The glossary will be called the Word Bin.), and learning scenarios (e.g. Just pretend we've got a newsletter.). In contrast to DK, CK frequencies decreased throughout the Moodle design weeks in both cycles. The percentages of CK distribution in the first week were almost three times larger than those of CK distribution in the last week (refer to Tables 4 and 5 in the Appendix for specific percentages). This pattern for DK, which is visually presented in Figs. 3 and 4 above, seems to be reflective of pre-service teachers having settled on their content in early weeks, enabling later discussions to focus on other areas.

\subsection{Pedagogical Knowledge (PK)}

There were many references to pedagogies in Cycle 1 and Cycle 2 (approximately $9 \%$ and $5 \%$ of the units coded respectively, as shown in Figs. 1 and 2). Each team discussed and compared various pedagogical perspectives in order to select an overarching pedagogical approach for their Moodle module (e.g. Yeah, I think a balanced approach would be fine, but I think the main one should be Social Constructivism). PK was also reflected in the way the groups discussed their teaching strategies (e.g. You'll probably drill it [the concept of tessellation] into them so much.) and how they repeatedly considered what types of assessment (diagnostic, formative, summative) to select as well as how to manage the classes. Participants similarly discussed what pedagogical perspectives to write about in their justifications for their technology-enhanced Moodle modules. For instance, one participant explained to her team via instant messaging about the alignment of a learning activity in their module in a very critical way: I think it's most aligned to constructivism because they are experiencing the sources [resources] and the information individually and then using social [communication] a little to construct meaning and 'real-life' it/enact it/apply it.

\subsection{Technological Knowledge (TK)}

As can be seen from Figs. 1 and 2, pre-service teachers placed as relatively much emphasis on technology as on pedagogy (8\% compared to slightly below 9\%) while working on their technology-enhanced designs together in Cycle 1 but shifted the 
emphasis away from pedagogy and toward technology in Cycle 2 with almost $5 \%$ of the units coded for PK and over $12 \%$ for TK. The teams' understanding of technology varied from a simple cognitive level such as labeling the tools to more sophisticated articulations related to what they knew about the tools (e.g. This one says with Crazy Talk teachers can make famous historical people come to life as funny talking animated characters.) and comparing the tools. Moreover, the participants were aware that if too many technologies were to be introduced into their online modules, the focus of the modules would possibly change to teaching technologies instead of teaching technology-enhanced content. For example, one participant questioned the possible shift in focus when she remarked, ...but then would you want it to be more like technology-based or more about all the teaching [technology] because it could go off track as well?

\subsection{Technological Pedagogical Content Knowledge (TPACK)}

Although the percentage of the units coded with TPACK was comparatively negligible - approximately 5\% and 2\% in Cycle 1 and Cycle 2 respectively as illustrated in Figs. 1 and $2-$ there were several interesting findings about TPACK. At a basic level, TPACK discussed in a sentence was as simple as technology being mentioned together with content and how content was delivered (pedagogy) (e.g. I'd do a quiz online or do a video on why someone doesn't wear a seat belt and then, 'Oh what's wrong with this?'). Although the participant referred to technology (online quiz, video), content (safety practice - why someone is not wearing a seat belt), and teaching strategies (a question to elicit responses from learners), other instances involved articulating whole design ideas in more specific and explicit manner (e.g. You could make a survey using something like SurveyMonkey, give it to the public, your parents, your friends, your sports coach, asking for some opinions about 'What's a cool place in our school zone that we could heritage site?'). Interestingly, this example that suggested what technology to use (SurveyMonkey) and pedagogy to deploy was articulated in the first week, indicating that TPACK sophistication was not necessarily dependent on stages of the design process.

\subsection{Technological Content Knowledge (TCK)}

TCK received approximately equal attention from the pre-service teachers as TPACK in Cycle 1 (5\% of the units coded), yet twice as much attention as TPACK in Cycle 2 (slightly over 4\% of the units coded), as indicated in Figs. 1 and 2. TCK emerged during conversations surrounding content-based digital tools and the use of technology for representing and storing content (e.g. I'm still going to play around with the Moodle to see how to control the access of content and see if I can find what you need). More specifically, emerging from these conversations was the discussion on how the technological affordances could accommodate the learning activity in discussion (e.g. I am looking at the Number and Algebra and thinking about what would be easy to assess and look at on Moodle site). Other times participants opted for a tool in place of one they were not fluent at using (e.g. I couldn't figure out 
how to use the Quiz for the revision task so I used the Feedback element that allows open end answers). The instances indicate that the pre-service teachers were flexible in making choices about what tools to use for certain learning activities and made decisions based upon what they wanted their potential learners to achieve out of the content.

\subsection{Pedagogical Content Knowledge (PCK)}

PCK received the second least attention compared to other TPACK elements in Cycle 1 and Cycle 2, constituting approximately 3\% and 3.5\% of the total units coded respectively (refer to Figs. 1 and 2). The PCK comments sometimes related to participants selecting a certain pedagogical approach for certain content and elaborating on why the approach should be used (e.g. Second, since the initial idea was to engage with this event/debate in history so that students would be able to think critically about current events/debates, maybe we should include something about this in Lesson 6, Slight Chance of Tact). Most importantly, the teams showed capacities to articulate the pedagogical perspective soundly in connection with content, for instance, taking into account how learning outcomes aligned with different cognitive levels in Anderson and Krathwohl's (2001) cognitive process model (e.g. So, anyway, this is just based on me trying to put the outcomes and the content into Anderson Krathwohl, trying to have it be in order of the cognitive processes that they're using from like lower order Understand up to Create at the end.).

\subsection{Technological Pedagogical Knowledge (TPK)}

As shown in Figs. 1 and 2, it was apparent that among the seven knowledge constructs in the TPACK framework, TPK was the least discussed in both cycles, receiving only $0.8 \%$ of the total distribution in Cycle 1 and $0.9 \%$ in Cycle 2. Despite its low frequencies, there were several interesting points to note about the pre-service teachers' discussions on TPK. Teams acknowledged the importance and effectiveness of technologies in facilitating the pedagogy implementation (e.g. assessment) in the classroom, with comments such as It [the development of technology] makes it easier for student assessment while bringing modern technology into the classroom. Importance was also placed on the consideration of technological affordances in the application of teaching approaches (e.g. Based on our affordances we can use [them] to facilitate pedagogies).

\subsection{Context}

It is apparent from Figs. 1 and 2 that the pre-service teachers did not discuss context as much as expected in both cycles (the units coded constituting only $1.9 \%$ for Cycle 1 and $0.7 \%$ for Cycle 2). A large proportion of the teams' conversations surrounding context occurred when the teams answered the two questions asked in the Learning Design Guide in Week 1, What is the context? and What are the best ways to promote students' motivation and engagement within that context? When 
answering the first question, the teams often referred back to the default context, and then added more characteristics to their potential learner cohorts. For example, one team decided on an English as an Additional Language or Dialect (EALD) group with mixed-ability students ranging from "people with learning difficulties and disabilities, EALD students to gifted students". This cohort was then the basis for selecting suitable materials and technologies for the target group. The participants' understanding of context was also associated with their elaborations on New South Wales primary schools' schedule (e.g. In school, do they aim to do one hour of technology a week or is it two hours of technology a week?), potential school facilities (e.g. We use iPads [in our Moodle design] because every child has access to one in many schools.), and learner cohort's background (e.g. The tutor said our context was like mixed abilities, mixed socio-economic statuses.) to provide rationales for their design decisions.

\section{Discussion}

\subsection{TPACK elements and Context}

Design Knowledge (DK) was the most frequently observed category of discourse (approximately $45 \%$ of the units coded) that occurred when pre-service teachers discussed issues relating to the management of design processes such as delegating tasks among each other, creating group chats, scheduling and setting goals, and other design issues such as discussing the aesthetic aspects of the designs. The high frequency of design discourse matches findings observed in some earlier studies (Koh \& Chai, 2016; Nguyen \& Bower, 2018), and confirms that there are considerably more than just TPACK discourse involved in teachers' collaborative design processes. If DK is such a large part of collaborative learning design processes, then it is prudent for teacher educators to explicitly and extensively focus on helping preservice teachers develop this knowledge and skills rather than exclusively focusing on TPACK. Knowing how to effectively design in teams is particularly relevant considering the increasing momentum towards collaborative design in the teaching workforce. The heightened presence of DK in this study versus its absence in other TPACK studies could be because of the context involving a collaborative learning design task. This connection has been claimed by Tseng et al. (2019). Alternately, it could be a result of the analytic lens that transcended the exclusive focus on TPACK elements to consider design as a distinct area of discourse.

Content Knowledge (CK) was a substantial component of the collaborative design conversations (over $24 \%$ and $27 \%$ of the units coded in Cycle 1 and Cycle 2). This finding was in line with studies on pre-service and in-service (kindergarten, primary, secondary, and university) teachers who placed considerable emphasis on content when developing their technology-enhanced materials (Graham et al., 2012; Harris \& Hofer, 2011; Koh \& Chai, 2016; McKenney et al., 2016). Thus, an emphasis on CK during learning design processes appears to be irrespective of participants' teaching level and experience. The emphasis on content related discourse primarily occurred in the early stages of the design process, where the pre-service teachers 
were deciding what to teach rather than how. This finding highlights the need for teacher educators to concentrate on content related scaffolding in earlier stages of the design process, such as syllabus interpretation, the degree of higher order thinking that will be engaged, and so on. In a study by Churchill (2006), experienced university teachers placed less emphasis on content, but this could be because selfreporting of importance was being used rather than analysis of actual design processes. This highlights the different findings that may arise when using primary analysis of process data rather than analysing participant perceptions.

In terms of Technological Knowledge (TK), its frequent occurrence (between $8 \%$ and $12 \%$ of total discourse in Cycle 1 and Cycle 2 respectively) was due to pre-service teachers taking time to search for the tools and critically compare technological alternatives. The fact that this was not integrated with pedagogical and content conversation is understandable, given the functionality of different tools is a good foundation for later TPK, TCK and TPACK thinking. We believe that it is necessary and sensible for pre-service teacher educators to take the opportunity to reflect purely on the functionality of technologies, initially unfettered by pedagogical and content related matters to avoid cognitive overload. However, we note that in studies of practising teachers by Janssen and Lazonder (2016) and Zhang et al. (2019), there were rarely observed any technology-related statements, which may be due to teachers' greater experience with using technology (reducing need to discuss it) or their more integrated treatment of technology. Thus, once pre-service teachers are familiar with technology, it is important for pre-service teacher educators to encourage more integrated TPK, TCK, and TPACK consideration to foster more expert thinking.

In regard to Pedagogical Knowledge (PK), the pre-service teachers in both Cycle 1 and Cycle 2 of the study explicitly articulated pedagogy-related issues (roughly $9 \%$ and $5 \%$ of the units coded respectively), demonstrating their knowledge of different pedagogical approaches in e-learning, teaching strategies and assessment methods. This finding was in contradiction with findings in a previous study of pre-service teacher design conversations, where pedagogy was hardly articulated (Nguyen \& Bower, 2018). On the other hand, the higher level of PK discussion is consistent with numerous studies in the field of Learning Design (Bennett et al., 2015; Churchill, 2006; Graham et al., 2012; Postareff \& Lindblom-Ylänne, 2008; Zhang et al., 2019) in a way that the participants in their studies also attended to pedagogy when designing teaching materials. Furthermore, in alignment with results observed in Bennett et al.'s (2015) study of experienced academics, the pre-service teachers in the current study showed an ability to deliberate over which pedagogical approaches would be employed in their learning activities and assessments, as well as which scholarly research would inform their discussions. This reinforces the need for teacher educators to provide strategies, or interventions, for pre-service teachers to articulate more pedagogy during their collaborative design work.

Unlike the separated knowledge elements, Technological, Pedagogical, and Content Knowledge (TPACK) had low frequency of occurrence (approximately 5\% and $2 \%$ in Cycle 1 and Cycle 2 respectively). This finding accords with observations by Janssen and Lazonder's (2016) study, though the percentage of the units coded as TPACK in this study were smaller compared to those of other studies (Graham et al., 2012; Koh \& Chai, 2016). 
Similarly, Technological Content Knowledge (TCK) did not receive as much attention from the pre-service teachers as DK, CK, PK, and TK $(5.0 \%$ in Cycle 1 and $4.1 \%$ in Cycle 2). This finding is in keeping with other studies of pre-service and experienced teacher collaborative technology-enhanced learning design, where frequencies of TCK were the lowest compared to all other TPACK elements (Koh \& Chai, 2016; Tseng et al., 2019; Zhang et al., 2019).

Among the seven knowledge constructs in the TPACK framework, Technological Pedagogical Knowledge (TPK) was the lowest in both cycles $(0.8 \%$ in Cycle 1 and $0.9 \%$ in Cycle 2). This finding also aligns with those of the previous studies that have examined in-service teachers' considerations of TPACK in their design conversations (Koh \& Chai, 2016; Tseng et al., 2019). These findings indicate that concurrent consideration of technology with other areas (content and pedagogy) is an important area on which to focus upon for developing pre-service teachers' integrated understanding of technology-enhanced learning design.

Pedagogical Content Knowledge (PCK) discourses received similarly low levels of utilisation in Cycle 1 and Cycle 2 of this study (2.9\% and 3.5\%, respectively). However, the low frequency of PCK was in contrast to earlier findings where it was found to be extensively articulated by both pre-service (Janssen \& Lazonder, 2016; Tseng et al., 2019) and practising teachers (Boschman et al., 2015; Koh \& Chai, 2016; Zhang et al., 2019). Koh \& Chai (2016) propose that the relatively large emphasis on PCK by practising teachers may be because they were more familiar with pedagogy and content, and less familiar with technology. In any case, pre-service teacher educators should be mindful of the need to develop and support the PCK understanding of their students where possible, and not assume that pre-service teachers enter their units with strong understanding of how pedagogy can be used to develop content knowledge (irrespective of technology use).

Taken together, it was clear that overall the second-order constructs (PCK, TPK, TCK) and the third-order construct of TPACK were much less articulated in both Cycle 1 and Cycle 2 (13.9\% and $10.6 \%$ of the units coded in the respective Cycles 1 and 2) compared to first order constructs of CK, PK, and TK $(41.6 \%$ and $44.7 \%$ in Cycle 1 and Cycle 2, respectively). This finding is in contrast to findings by Boschman et al. (2015) that the participating teachers of 30 years' teaching experience on average spent most of their time on discussing PCK and TPACK while scarcely mentioning CK, TK, and PK. This suggests more experienced teacher better understood how technology, pedagogy, and subject-matter should be integrated while less experienced young teachers were still learning and revisiting their knowledge of each single domain in isolation. This would imply that teacher educators should apply strategies to encourage pre-service teachers to articulate more of these integrated TPACK constructs based on their available TK PK and CK competencies, for instance, through explicit tasks that ask students to justify particular technology selections in terms of their content and pedagogy choices.

In this study, Context was rarely mentioned by the pre-service teachers, aligning with the finding in Nguyen and Bower's (2018) analysis. The frequency of Context-related discourses was unexpectedly low in both Cycle 1 and Cycle 2 (the units coded constituting only $1.9 \%$ for Cycle 1 and $0.7 \%$ for Cycle 2) despite attempts to more greatly emphasise context in Cycle 2, where two real-life schools were 
included in the design brief. The low levels of contextual discussion may have been because the clearly-defined context was assumed in all conversations once that context was established, and the provision of more details about context in Cycle 2 may have actually reduced the need for pre-service teachers to discuss Context. However, given the critical importance of considering Context in design processes, we recommend both specifying an authentic design context as well as asking prompting questions to promote deep contextual analysis.

\subsection{A Proposed D-TPACK framework}

The dominant presence of Design Knowledge (DK) in this study suggests that design represents an important consideration that cannot be ignored when seeking to understand how TPACK knowledge is applied in practice. Moreover, both the literature reviewed and findings of this study speak to the influence of Context as a lens through which teacher educators, in-service, and pre-service teachers alike view their work. Context also operates as a mediator that influences the TPACK constructs that are deemed important, along with other aspects such as the educator's level of experience, stage of the learning design process, nature of the work being undertaken, and the role of collaboration. When viewed alongside similar findings in the field, the complex interplay observed in this study strongly points to the need for an augmentation of the TPACK model that encompasses both DK and Context.

One possible augmented framework that includes TPACK and DK interwoven with Context as a surrounding element could tentatively be named the D-TPACK Framework (see Fig. 5 below). By extending existing frameworks to encompass the actual learning design processes of teachers, D-TPACK could provide deeper and broader understandings of how teachers approach technology-based learning design and thereby address limitations of the TPACK framework (Boschman et al., 2015). Although all forms of TPACK knowledge are instrumental to effective learning design, it is not until knowledge is applied in practice that it moves from being static to pragmatic and fluid (Bower, 2017). Thus, thinking of learning design purely in terms of the TPACK framework arguably obscures how much practical procedural design thinking needs to occur during the real-world practice of technologyenhanced learning design. The D-TPACK framework seeks to highlight that learning design not only involves teacher application of TPACK understanding, but also their knowledge of context, learners' characteristics, and design considerations (attending to aesthetic elements as well as the management of design processes), with validation provided by the empirical findings of this study.

Although D-TPACK is a developmental model, the inclusion of Context and DK accords with previous findings such as Chai and Koh (2017), who found that preservice teachers were ready to accept their roles as designers with the beliefs that teachers should be entrusted with designing their own lessons, be responsible for the quality of the design packages, and acquire design expertise. The D-TPACK framework has the potential to foreground the importance of teacher education programs engaging teachers as designers, providing them with design knowledge and practice 
among other essential knowledge elements such as TPACK elements (as shown in Fig. 5).

Found amongst the design conversations of our study were several design patterns, such as sharing background knowledge, distributing tasks, planning team communication, establishing common-ground awareness and documenting design drafts. According to Hoadley and Cox (2009), design patterns are a type of design knowledge and "a template solution to a common problem" (p. 27). Evidently, all the pre-service teacher teams in the current study utilised certain design patterns in seeking solutions to several problems emerging from the collaborative design process. This finding together with DK being most frequently referenced suggests the importance for pre-service teachers as learning designers to possess knowledge other than TPACK to undertake the whole design process smoothly and effectively. As part of DK, design patterns can be explicitly discussed by teacher educators who could direct pre-service teachers' attention to these patterns during teacher education

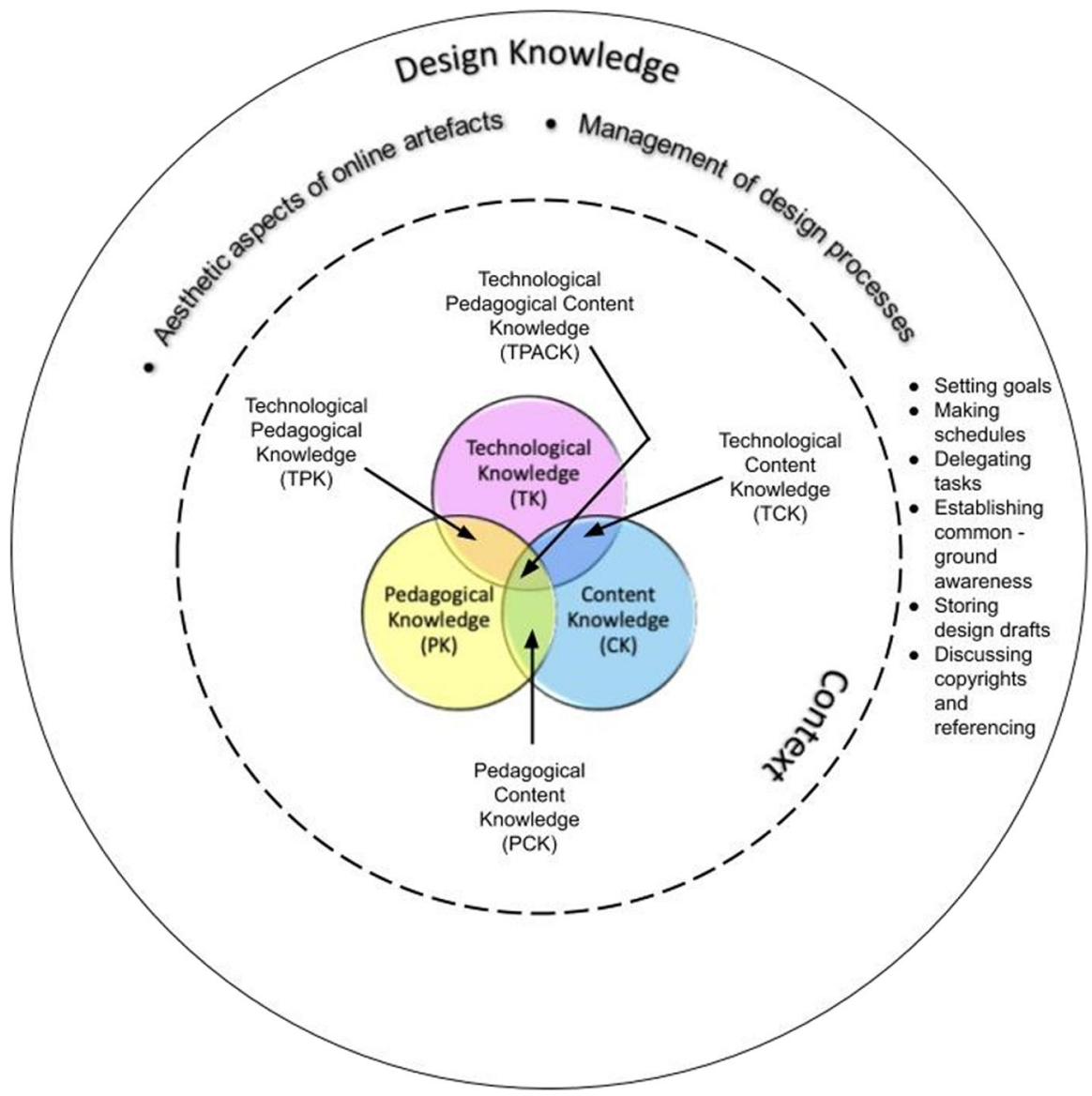

Fig. 5 The D-TPACK framework 
courses. Pre-service teacher DK (and TPACK) could also potentially be fostered via metacognitive prompts, reflection, tutoring, modelling and collaboration (Chai et al., 2019; Kramarski \& Michalsky, 2010). In the future, we can also expect that machine learning and big data will play an increasingly important role in informing teacher's learning design decisions and knowledge (for instance, see Goldberg et al., 2021; Kalhoro et al., 2016; Kausar et al., 2018).

\subsection{Future research}

This study points to several key areas for further research. First, further research could examine how the application of the D-TPACK framework - that is, encompassing all TPACK constructs in addition to both Design Knowledge (DK) and Context-contributes to understanding of teachers' learning design thinking and practices. D-TPACK is useful from a both practitioner and researcher perspectives. Studies might explore practitioner application of D-TPACK-based through technology-based design approaches similar to those explored in this study. From a researcher perspective, new approaches to measuring Context and DK might be developed to enrich both existing and future approaches to measuring TPACK. Such research could be also carried out with teachers at all career stages, and valid ways of measuring Context could in turn facilitate more objective analysis of findings across a wide range of educational contexts.

This study also provides a detailed framework for analysing teachers' learning design discourses that can be used in future studies. The specific frequencies of discourses in each category provide a baseline for comparison with other cohorts and for different treatments. For instance, if teacher educators apply different approaches in different iterations, it may be possible to use the framework to detect statistically significant differences in design behaviours, including the proportions of different sorts of discourse and when they occur. This may be used to provide objective measures of impact, for instance, that certain teacher education strategies lead to more integrated TPACK consideration.

Methodologically, it is recommended that further research be undertaken in the following areas. First, other coding units besides sentence level coding could be explored for the studies that investigate the nature of teacher design conversations via thematic/content/discourse analysis using the D-TPACK elements as themes. Although coding using sentences as unit of analysis is fine grained thus providing somewhat objective and consistent unit sizes, some meanings can be lost when the larger idea (e.g. discussions on synthesised knowledge elements like TPK, TCK, PCK and TPACK) is expressed in a cluster of sentences. Therefore, alternative approaches to analysing discourse could be explored to more accurately capture semantics such as topic exchanges or discourse episodes.

Collaborative design of technology-enhanced modules among in-service teachers could be examined in a similar way. A real-life teaching and learning environment together with authentic learning design products that would be directly applied to classrooms could lead to different results in terms of design focuses, design approaches, and supporting and inhibiting factors. This could in turn lead 
to interesting findings about differences between experienced and novice teachers, and hence the sorts of strategies that teacher educators may need to apply for each cohort. There is also an opportunity for DK to be explored in a self-reported "Design-TPACK" surveys, which has never happened in the literature to date.

\section{Conclusions}

This study reveals the elements that pre-service teachers focused upon during their extended collaborative technology-enhanced learning design conversations. Across two separate cycles, Design Knowledge (DK) was the most frequent focus of conversations, followed by the TPACK single constructs (CK, PK, TK), with relatively minor focus upon the integrated constructs (TPK, TCK, PCK, TPACK) and Context. The study also revealed patterns of concentration, for instance, heavier emphasis upon CK discussion in earlier stages of the groupwork project and greater emphasis on DK discourses in later stages. These findings, and the detailed characterisation of pre-service teacher design conversations that emerged from the coding and analysis, led to specific suggestions for teacher education. These included focusing on DK within pre-service teacher education programs in addition to TPACK, as well as various strategies to improve pre-service teacher integrated TPACK elements based on their existing knowledge of technology, content, and pedagogy. A detailed coding framework and a D-TPACK model were proposed, that extend beyond the popular TPACK framework to incorporate the very real amount of design knowledge and discourse that occurs when teachers collaboratively design together. The study also highlights significant opportunities for further empirical research to extend theoretical and practical understanding of learning design in connection with the TPACK framework.

The current study has made several contributions to the teacher education and learning design research fields. A key strength of this study is that it examined the pre-service teachers' actual learning design process via a comprehensive thematic analysis of nearly 50 'live' collaborative design conversations. These conversations were over an extended timeframe and captured much, if not all, of the design discourse of the groups to characterise their nature using an abductive and exhaustive coding process. This in itself is a unique contribution to educational research. More generally, the patterns of discourse observed in this study help to better understand the authentic nature of design processes, and hence identify strategies to support the development of teachers' technology-enhanced learning design capabilities. The detailed methodological framework can enable comparisons between different cohorts and teacher education approaches. Furthermore, the study further established and clarifies the connection between the TPACK framework and Learning Design, especially with relation to collaborative design practices. This was reflected, for instance, through the identification of DK that dominantly characterised the preservice teacher design conversations and the need for an augmented model - the $D$-TPACK framework - to encompass all key forms of knowledge explored. The prevalence of DK not only confirms the importance of DK with relation to TPACK while teachers are designing their technology-enhanced lessons, but highlights the 
need to understand how pre-service teachers approach their design through Context. Both DK and Context enrich existing understanding of the technology-based learning design process and underscore an evidence-based approach that can be replicated in other teacher education programs.

\section{Appendix}

Table 4 Distribution of design focus over 5 weeks in Cycle 1

\begin{tabular}{lllllll}
\hline Cycle 1 & Week 1 & Week 2 & Week 3 & Week 4 & Week 5 & Total \\
\hline DK & 35.8 & 26.4 & 30.8 & 44.8 & 62.1 & 42.8 \\
CK & 43.2 & 22.5 & 18.5 & 23.1 & 15.2 & 24.3 \\
PK & 5.8 & 9.8 & 13.4 & 7.7 & 8.5 & 8.8 \\
TK & 5.9 & 16.7 & 15.6 & 7.5 & 2.6 & 8.5 \\
TPACK & 2.9 & 6.9 & 5.4 & 6.5 & 5.0 & 5.2 \\
TCK & 3.3 & 10.1 & 6.3 & 4.4 & 2.5 & 5.0 \\
PCK & 0.9 & 1.6 & 8.7 & 3.0 & 1.5 & 2.9 \\
TPK & 0.1 & 2.4 & 0.5 & 0.7 & 0.8 & 0.8 \\
C & 2.1 & 3.6 & 0.8 & 1.3 & 1.8 & 1.9 \\
\hline
\end{tabular}

Table 5 Distribution of design focus over 6 weeks in Cycle 2

\begin{tabular}{llllllll}
\hline Cycle 2 & Week 1 & Week 2 & Week 3 & Week 4 & Week 5 & Week 6 & Total \\
\hline DK & 38.9 & 32.6 & 31.6 & 67.1 & 41.7 & 50.2 & 44.0 \\
CK & 40.8 & 45.0 & 38.1 & 12.6 & 16.6 & 13.2 & 27.4 \\
PK & 6.5 & 5.0 & 6.2 & 7.2 & 0.9 & 3.6 & 4.9 \\
TK & 9.1 & 8.6 & 11.4 & 9.8 & 20.0 & 15.9 & 12.4 \\
TPACK & 1.9 & 2.2 & 2.1 & 0.0 & 3.3 & 2.9 & 2.1 \\
TCK & 0.3 & 2.2 & 3.2 & 1.7 & 11.8 & 5.8 & 4.1 \\
PCK & 0.5 & 3.8 & 4.4 & 1.5 & 3.0 & 7.1 & 3.5 \\
TPK & 0.8 & 0.5 & 2.3 & 0.0 & 1.4 & 0.5 & 0.9 \\
C & 1.2 & 0.1 & 0.8 & 0.1 & 1.4 & 0.8 & 0.7 \\
\hline
\end{tabular}

\section{Declarations}

Conflict of interest No conflicts of interest arose during the execution of this research. 


\section{References}

Anderson, L. W., \& Krathwohl (Eds.). (2001). A taxonomy for learning, teaching, and assessing: A revision of Bloom's taxonomy of educational objectives. Longman

Asensio-Pérez, J. I., Dimitriadis, Y., Pozzi, F., Hernández-Leo, D., Prieto, L. P., Persico, D., \& VillagráSobrino, S. L. (2017). Towards teaching as design: Exploring the interplay between full-lifecycle learning design tooling and Teacher Professional Development. Computers \& Education, 114, 92-116. https://doi.org/10.1016/j.compedu.2017.06.011

Bennett, S. (2013). Teacher design thinking: The design processes of expert school teachers. Educational Media (ICEM), 2013 IEEE 63rd Annual Conference International Council for Educational Media (ICEM), 1-1. https://doi.org/10.1109/CICEM.2013.6820226

Bennett, S., Agostinho, S., \& Lockyer, L. (2015). Technology tools to support learning design: Implications derived from an investigation of university teachers' design practices. Computers \& Education, 81, 211-220. https://doi.org/10.1016/j.compedu.2014.10.016

Bennett, S., Agostinho, S., \& Lockyer, L. (2016). The process of designing for learning: Understanding university teachers' design work. Educational Technology Research and Development, 1-21. https:// doi.org/10.1007/s11423-016-9469-y

Bennett, S., Thomas, L., Agostinho, S., Lockyer, L., Jones, J., \& Harper, B. (2011). Understanding the design context for Australian university teachers: Implications for the future of learning design. Learning, Media and Technology, 36(2), 151-167. https://doi.org/10.1080/17439884.2011.553622

Boschman, F., McKenney, S., \& Voogt, J. (2015). Exploring teachers' use of TPACK in design talk: The collaborative design of technology-rich early literacy activities. Computers \& Education, 82, 250-262. https://doi.org/10.1016/j.compedu.2014.11.010

Bower, M. (2009). Discourse analysis of teaching computing online. Computer Science Education, 19(2), 69-92. https://doi.org/10.1080/08993400902909500

Bower, M. (2012). A framework for developing pre-service teachers' Web 2.0 learning design capabilities. In Developing technology-rich teacher education programs: Key issues (pp. 58-76). IGI Global

Bower, M. (2017). Design of technology-enhanced learning: Integrating research and practice. Emerald Publishing. http://bit.ly/DesignOfTEL

Bower, M., Craft, B., Laurillard, D., \& Masterman, L. (2011). Using the Learning Designer to develop a conceptual framework for linking learning design tools and systems. http://www.researchonline.mq. edu.au/vital/access/services/Download/mq:17513/DS01

Boyle, T., \& Ravenscroft, A. (2012). Context and deep learning design. Computers \& Education, 59(4), 1224-1233. https://doi.org/10.1016/j.compedu.2012.06.007

Braun, V., \& Clarke, V. (2006). Using thematic analysis in psychology. Qualitative Research in Psychology, 3(2), 77-101. https://doi.org/10.1191/1478088706qp063oa

Chai, C. S., Ling Koh, H., \& Teo, Y. H. (2019). Enhancing and modeling teachers' design beliefs and efficacy of Technological Pedagogical Content Knowledge for 21 st century quality learning. Journal of Educational Computing Research, 57(2), 360-384. https://doi.org/10.1177/07356 33117752453

Chai, C. S., \& Koh, J. H. L. (2017). Changing teachers' TPACK and design beliefs through the Scaffolded TPACK Lesson Design Model (STLDM). Learning: Research and Practice, 3(2), 114129. https://doi.org/10.1080/23735082.2017.1360506

Churchill, D. (2006). Teachers' private theories and their design of technology-based learning. British Journal of Educational Technology, 37(4), 559-576

Dagnino, F. M., Dimitriadis, Y. A., Pozzi, F., Asensio-Pérez, J. I., \& Rubia-Avi, B. (2018). Exploring teachers' needs and the existing barriers to the adoption of Learning Design methods and tools: A literature survey. British Journal of Educational Technology, 49(6), 998-1013. https://doi.org/ 10.1111/bjet.12695

Goldberg, P., Sümer, Ö., Stürmer, K., Wagner, W., Göllner, R., Gerjets, P. ... Trautwein, U. (2021). Attentive or not? Toward a machine learning approach to assessing students' visible engagement in classroom instruction. Educational Psychology Review, 33(1), 27-49. https://doi.org/10.1007/ s10648-019-09514-Z

Graham, C. R., Borup, J., \& Smith, N. B. (2012). Using TPACK as a framework to understand teacher candidates' technology integration decisions. Journal of Computer Assisted Learning, 28(6), 530-546. https://doi.org/10.1111/j.1365-2729.2011.00472.x 
Harris, J. B., \& Hofer, M. J. (2011). Technological pedagogical content knowledge (TPACK) in action. Journal of Research on Technology in Education, 43(3), 211-229. https://doi.org/10. 1080/15391523.2011.10782570

Hoadley, C., \& Cox, C. (2009). What is design knowledge and how do we teach it? In C. DiGiano, S. Goldman, \& M. Chorost (Eds.), Educating learning technology designers: Guiding and inspiring creators of innovative educational tools (pp. 19-35). Routledge

ISTE (2022). ISTE standards for educators. https://www.iste.org/standards/for-educators. Accessed 26 Feb 2022

Janssen, N., \& Lazonder, A. W. (2016). Supporting pre-service teachers in designing technologyinfused lesson plans. Journal of Computer Assisted Learning, 32(5), 456-467. https://doi.org/10. $1111 /$ jcal.12146

Kalhoro, A. A., Rajper, S., \& Mallah, G. A. (2016). Detection of e-learners' learning styles: An automatic approach using decision tree. 14(8), 7

Katsamani, M., Retalis, S., \& Boloudakis, M. (2012). Designing a Moodle course with the CADMOS learning design tool. Educational Media International, 49(4), 317-331. https://doi.org/10.1080/ 09523987.2012.745771

Kausar, S., Huahu, X., Hussain, I., Wenhao, Z., \& Zahid, M. (2018). Integration of data mining clustering approach in the personalized e-learning system. IEEE Access, 6, 72724-72734. https://doi. org/10.1109/ACCESS.2018.2882240

Koehler, M. J., \& Mishra, P. (2009). What is technological pedagogical content knowledge? Contemporary Issues in Technology and Teacher Education, 9(1), 60-70

Koh, J. H. L., \& Chai, C. S. (2016). Seven design frames that teachers use when considering technological pedagogical content knowledge (TPACK). Computers \& Education, 102, 244-257. https://doi.org/10.1016/j.compedu.2016.09.003

Koh, J. H. L., Chai, C. S., \& Tay, L. Y. (2014). TPACK-in-Action: Unpacking the contextual influences of teachers' construction of technological pedagogical content knowledge (TPACK). Computers \& Education, 78, 20-29. https://doi.org/10.1016/j.compedu.2014.04.022

Kramarski, B., \& Michalsky, T. (2010). Preparing preservice teachers for self-regulated learning in the context of technological pedagogical content knowledge. Learning and Instruction, 20(5), 434-447. https://doi.org/10.1016/j.learninstruc.2009.05.003

Landis, J. R., \& Koch, G. G. (1977). The measurement of observer agreement for categorical data. Biometrics, 33(1), 159-174. JSTOR. https://doi.org/10.2307/2529310

Laurillard, D. (2013). Teaching as a design science: Building pedagogical patterns for learning and technology. Routledge

Maguire, M., \& Delahunt, B. (2017). Doing a thematic analysis: A practical, step-by-step guide for learning and teaching scholars. AISHE-J: The All Ireland Journal of Teaching and Learning in Higher Education, 9(3). http://ojs.aishe.org/index.php/aishe-j/article/view/335

McKenney, S., Boschman, F., Pieters, J., \& Voogt, J. (2016). Collaborative design of technologyenhanced learning: What can we learn from teacher talk? TechTrends, 60(4), 385-391. https:// doi.org/10.1007/s11528-016-0078-8

McKenney, S., Kali, Y., Markauskaite, L., \& Voogt, J. (2015). Teacher design knowledge for technology enhanced learning: An ecological framework for investigating assets and needs. Instructional Science, 43(2), 181-202. https://doi.org/10.1007/s11251-014-9337-2

Mishra, P., \& Koehler, M. J. (2006). Technological pedagogical content knowledge: A framework for teacher knowledge. Teachers College Record, 108(6), 1017

Nguyen, G. N. H. (2020). Supporting the development of pre-service teacher learning design capabilities [Doctor dissertation, Macquarie University]. http://hdl.handle.net/1959.14/1284005

Nguyen, G. N. H., \& Bower, M. (2018). Novice teacher technology-enhanced learning design practices: The case of the silentpedagogy. British Journal of Educational Technology, 49(6), 10271043. https://doi.org/10.1111/bjet.12681

Nowell, L. S., Norris, J. M., White, D. E., \& Moules, N. J. (2017). Thematic analysis: Striving to meet the trustworthiness criteria. International Journal of Qualitative Methods, 16(1), 1609406917733847. https://doi.org/10.1177/1609406917733847

Postareff, L., \& Lindblom-Ylänne, S. (2008). Variation in teachers' descriptions of teaching: Broadening the understanding of teaching in higher education. Learning and Instruction, 18(2), 109-120. https://doi.org/10.1016/j.learninstruc.2007.01.008 
Rosenberg, J. M., \& Koehler, M. J. (2015). Context and technological pedagogical content knowledge (TPACK): A systematic review. Journal of Research on Technology in Education, 47(3), 186-210. https://doi.org/10.1080/15391523.2015.1052663

Shulman, L. S. (1986). Those who understand: Knowledge growth in teaching. Educational Researcher, 15(2), 4. https://doi.org/10.2307/1175860

Svihla, V., Reeve, R., Sagy, O., \& Kali, Y. (2015). A fingerprint pattern of supports for teachers' designing of technology-enhanced learning. Instructional Science, 43(2), 283-307. https://doi.org/10. 1007/s11251-014-9342-5

Tondeur, J., Scherer, R., Siddiq, F., \& Baran, E. (2020). Enhancing pre-service teachers' technological pedagogical content knowledge (TPACK): A mixed-method study. Educational Technology Research and Development, 68(1), 319-343. https://doi.org/10.1007/s11423-019-09692-1

Tondeur, J., van Braak, J., Sang, G., Voogt, J., Fisser, P., \& Ottenbreit-Leftwich, A. (2012). Preparing pre-service teachers to integrate technology in education: A synthesis of qualitative evidence. Computers \& Education, 59(1), 134-144. https://doi.org/10.1016/j.compedu.2011.10.009

Tseng, J. J., Cheng, Y. S., \& Yeh, H. N. (2019). How pre-service English teachers enact TPACK in the context of web-conferencing teaching: A design thinking approach. Computers \& Education, 128, 171-182. https://doi.org/10.1016/j.compedu.2018.09.022

UNESCO (2018). UNESCO ICT competency framework for teachers. United Nations Educational, Scientific and Cultural Organization. https://unesdoc.unesco.org/ark:/48223/pf0000265721

Zhang, S., Liu, Q., \& Cai, Z. (2019). Exploring primary school teachers' technological pedagogical content knowledge (TPACK) in online collaborative discourse: An epistemic network analysis. British Journal of Educational Technology, 50(6), 3437-3455. https://doi.org/10.1111/bjet.12751

Publisher's note Springer Nature remains neutral with regard to jurisdictional claims in published maps and institutional affiliations. 